\title{
Özgün Çalışma
}

\section{Direkt ve indirekt ölçümlerle ölçülen diyastolik kan basınçları korele değil}

\section{There is no correlation between non invasive diastolic blood pressure and invasive diastolic blood pressure}

\author{
İbrahim Yildırım \\ Sağlık Bilimleri Üniversitesi Tıp Fakültesi, Dr. Abdurrahman Yurtaslan Ankara Onkoloji SUAM \\ İç Hastalıkları
}

\begin{abstract}
Introductıon: There are several indirect and non-invasive techniques measuring blood pressure. The most popular non-invasive technique for routine examinations and monitoring is auscultation of Korotkoff sounds. We compared non-invasive and invasive systolic and diastolic blood pressure measurements in this study.

Methods: 46 adult patients to be operated on for any reason in Bulent Ecevit University Hospital were included in the study. The study patients' age, gender, height, weight and body mass index were recorded. Blood pressure was directly measured from radial arter and indirectly measured from brachial artery via a automated oscillometric device. Invasive and non-invasive blood pressure and pulse measurements were performed simultaneously. Median systolic and diastolic blood pressures obtained from all patients by both methods.

Results: Mean non-invasive systolic blood pressure was $114,6 \pm 18,72 \mathrm{mmHg}$, mean invasive systolic blood pressure was $116,1 \pm 18,08 \mathrm{mmHg}$, mean non-invasive diastolic blood pressure was $69,42 \pm 11,31$ $\mathrm{mmHg}$, mean invasive diastolic blood pressure was $63,81 \pm 12,26 \mathrm{mmHg}$ in the study patients. The difference between mean invasive and non-invasive systolic blood pressure wasn't significant $(p=0,28)$ but the difference between mean invasive and noninvasive diastolic blood pressure was statistically significant $(\mathrm{p}<0,001)$.

Discussion and conclusion: Although there was a significant correlation between invasive and noninvasive systolic pressure, there was no correlation between invasive and non-invasive diastolic pressure. Direct diastolic pressure measurement should be performed in patients with diastolic blood pressure abnormality.
\end{abstract}

Keywords: Hypertension, diastolic blood pressure, invasive blood pressure

\section{ÖZET}

Giriş ve amaç: Kan basıncını indirekt ve invaziv olmayan yöntemlerle ölçen çok sayıda teknik vardır. Günümüzde yaygın olarak kullanılan ve invaziv olmayan kan basıncı ölçümü olan Korotkoff seslerinin oskültasyonudur. Bu çalışmada noninvaziv yöntemlerle elde edilen sistolik ve diyastolik kan basıncı değerlerinin, intraarteryel ve direkt olarak ölçülen sistolik ve diyastolik kan basıncı değerlerinin karşılaştırılması ve aralarındaki korelasyonun incelenmesi amaçlandı.

Yöntem ve gereçler: Çalışmaya Bülent Ecevit Üniversitesi Tıp fakültesi hastanesinde herhangi bir nedenle opere edilen erişkin toplam 46 hasta alındı. Hastaların yaş, boy, kilo ve BMI değerleri belirlendi. Operasyon sirasında radiyal arterden direkt olarak, diğer koldan brakial arterden osilometrik cihazla indirekt olarak kan basınçları ve nabızları eş zamanlı olarak ölçüldü. Tüm hastalarda belirli aralıklarla toplam 15 ölçüm yapıldı. Her hastanın direkt ve indirekt olarak bakılan sistolik ve diyastolik kan basınçları ortalamaları alınarak karşılaştırıldı. Arteryel ile direkt ve koldan manşonlu tansiyon aleti ile indirekt kan basıncı ölçüm farkları bağımlı gruplarda Wilcoxon sıralı test istatistiği ile değerlendirildi.

Bulgular: Çalışmaya katılan hastaların koldan manşonla ölçülen sistolik kan basıncı ortalaması $114,6 \pm 18,72 \mathrm{mmHg}$, direkt yöntemle ölçülen ortalama sistolik kan basınc1 116,1 $18,08 \mathrm{mmHg}$ iken,

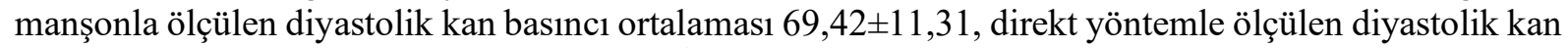
basınc1 ortalaması $63,81 \pm 12,26 \mathrm{mmHg}$ idi. İnvaziv ve noninvaziv yöntemlerle ölçülen sistolik basınç 
ortalaması arasında anlamlı bir fark yokken $(\mathrm{p}=0,28)$, diyastolik basınç ortalaması arasında anlamlı bir farkl111k vard1 $(\mathrm{p}<0,001)$.

Tartışma ve sonuç: İnvaziv olmayan yöntemlerle ölçülen sistolik kan basınçları gerçek sistolik basınç değerlerini yansıtırken, indirekt yollardan ölçülen diyastolik kan basınçları gerçek diyastolik basınçları ile korele değildir. Diyastolik kan basıncı anormallikleri düşünülen hastalarda doğrudan diyastolik kan basıncının ölçülmesinde fayda vardır.

Anahtar Kelimeler: Diyastolik kan basınc1, hipertansiyon, invaziv kan basınc1

\section{Giriş ve Amaç}

Kan basıncı invaziv olmayan birçok yöntemle ölçülebilir. Sfigmomanometri yöntemleri, palpasyon yöntemi, osilometri, pletismografi, doppler yöntemleri bu yöntemler arasında sayılabilir. Arteryel kan basıncının ölçümünde kullanılan en yaygın yöntem Korotkoff seslerinin oskültasyonudur. $\mathrm{Bu}$ yöntemde; bir distal arter üzerine yerleştirilen stetoskop ile kaf söndürülürken arteryel kanın boş damar yatağı içine birden akarken oluşturduğu seslerin duyulduğu basınç değerleri ölçülerek sistolik ve diyastolik kan basınçları bulunur.

Erișkin ve çocuk hastalarda noninvaziv kan basıncı ölçüm yöntemlerini kendi aralarında karşılaştıran pek çok çalışma yapılmıştır. Oskültometrik kan basıncı ölçümlerinden elde edilen sistolik kan basıncı değerleri gerçek sistolik basınçtan biraz düşüktür (1). Ancak invaziv ölçümlerle karşılaştırmalar çok enderdir. Bu çalışmaların bir tanesinde çocuklarda otomatik osilotonometrik basınç ölçümünü, direkt arteryel ölçümlerle karşılaştırılmış, ölçümlerin \%4-9'unda $10 \mathrm{mmHg}$ 'dan daha büyük farklılıklar olduğunu saptanmıştır (1). Osilometrik cihazların yüksek kan basınçlarında daha düşük, düşük kan basınçlarında ise daha yüksek basınçlar okuduğu gösterilmiştir (1). Obezite, hipertansiyon, hipotermi ve şok durumlarında da iki yöntem arasında farkl1lıklar bulunduğu bildirilmiştir (1).

Hipertansiyonun siniflaması ve evrelemesi, morbidite ve mortalite üzerine olan etkileri şimdiye kadar manşonlu tansiyon aletleri ile yapılan kan basıncı ölçümleri ile yapılmıştır. Son derece yaygın olarak kullanılan bu oskültometrik indirekt ölçümlerde sistolik kan basınc1, direkt ölçümlerle iyi korelasyon gösterse de bazı çalışmalarda diyastolik kan basını değerlerinde bu iyi korelasyon gösterilememiştir (2) Ancak bu iddiayı dile getiren çalışma sayısı çok azdır. Yine, oskültometrik yöntemlerle saptanan diyastolik kan basınçlarının ileri yaşlarda güvenirliğini yitirdiği bilinmektedir.

Direkt ve indirekt tekniklerle ölçülen diyastolik kan basınçlarının birbiri ile ne kadar korele olduğu hakkında günümüzde akıllarda bazı soru işaretleri bulunmaktadır. $\mathrm{Bu}$ konunun irdelenmesi ve bir netliğe kavuşması gerekmektedir. $\mathrm{Bu}$ araştırmada klasik manşonlu tansiyon aletleri kullanılarak elde edilen diyastolik kan basıncı değerlerinin, intraarteryel basınç ölçerlerce elde edilen diyastolik kan basıncı değerleri ile korelasyonunun değerlendirilmesi amaçlanmıştır.

İstatistik

Arteryel ile direkt ve koldan manşonlu tansiyon aleti ile indirekt kan basıncı ölçüm farkları bağımlı gruplarda Wilcoxon siralı test istatistiği ile ortancaları karşılaştırıldı. Kalp hızı, vücut kitle indeksi (BMI), yaş ile kan basınçları arasındaki ilişkiler Spearman korelasyon analizi ile değerlendirildi. $\mathrm{p}=0.05$ 'den küçük olan değerler istatisktiksel olarak anlamlı kabul edildi.

\section{Gereç ve Yöntem}

$\mathrm{Bu}$ çalışmanın etik kurul izni Bülent Ecevit Üniversitesi Tıp Fakültesinden alınmıştır.

Bülent Ecevit Üniversitesi Tıp Fakültesi hastanesinde opere edilen ve operasyon sirasında intraarteryel kan basincı izlemi yapılan 18 yaş üzeri hastalar çalışmaya alındı. Çalışmaya toplam 46 hasta dahil edildi. İntraarteryel kan basıncı izlemi radyal artere yerleştirilen bir kanülle sağlandı. İntraarteryel kan basınçları izlenmeye başlandığ 1 andan itibaren karşı kolda manşonlu otomatik tansiyon aleti ile brakial arterden, her 5 
Tablo 1: Hastalarının demografik bilgileri ve kan basme ortalamaları

\begin{tabular}{lll}
\hline & Ortalama $( \pm$ SS $)$ & Min-Max \\
\hline Yaș (yıl) & $66,48( \pm 13,05)$ & $26-86$ \\
\hline Boy $(\mathrm{cm})$ & $161,92( \pm 17,22)$ & $68-180$ \\
\hline Kilo (kg) & $73,97( \pm 21,52)$ & $40-165$ \\
\hline Nabiz (atım dak) & $76,43( \pm 15,39)$ & $51-126$ \\
\hline Noninvaziv SKB & $114,65( \pm 18,72)$ & $87,53-170,80$ \\
\hline Noninvaziv DKB & $69,42( \pm 11,31)$ & $44,87-90,07$ \\
\hline Invaziv SKB & $116,12( \pm 18,08)$ & $82,63-163,87$ \\
\hline Invaziv DKB & $63,81( \pm 12,26)$ & $40,9-106,73$ \\
\hline
\end{tabular}

SKB: Sistolik kan bastncl, DKB; diyastolik kan basinct. Kan basmcl birimi mmHg dir, SS:

Standart sapma.

dakikada bir ölçüm yapıldı. Direkt ve indirekt kan basınçları eş zamanlı olarak ölçülerek kaydedildi. İnvaziv sistolik ve diyastolik kan basınçları Datex Ohmeda $\mathrm{S} / 5$ anesthesia monitörü kullanılarak değerlendirildi. Her hastadan 30 ile 50 dakikalık bir süre aralığında ortalama 15 adet kan basıncı değeri alındı. Hasta verileri toplandiktan sonra indirekt ve intraarteriel kan basıncı değerleri kendi aralarında birbiriyle kıyasland 1 .

\section{Sonuçlar}

Bu çalışmada hastaların operasyon sırasındaki kan basıncı değişkenlikleri iki farklı yöntemle aynı anda ölçülerek değerlendirildi. Bir yöntemde intraarteryel producer ile direkt ölçümler, diğer yöntemde ise karşı koldan rutinde kullanılan manşonla indirekt ölçümler kaydedildi. Hastaların yaş, boy, kilo, nabız hizı ve tansiyon ortalamaları Tablo 1'de verilmiştir.

Bütün hastaların kayıt sırasındaki her iki yöntemle ölçülen sistolik ve diyastolik kan basıncı ortancaları şekil 1 ve 2'de gösterilmiştir.

İntraarteryel sistolik kan basıncı ortalaması ile manşonla ölçülen sistolik kan basıncı ortancaları arasinda anlamlı bir fark yoktu $(110,47 \mathrm{mmHg}$ 'ye $113,53 \mathrm{mmHg}, \mathrm{p}=0.107)$. İntraarteryel diyastolik kan basıncı ortancaları ile manşonla ölçülen diyastolik kan basıncı ortancaları arasında anlamlı bir fark tespit edildi $(67,16 \mathrm{mmHg}$ ile $61,09 \mathrm{p}<0,001)$.

Korelasyon analizlerinde her iki yöntemle bakılan sistolik kan basınçları birbiri ile korele iken (r:0.876, $\mathrm{p}<0.001)$ diyastolik kan basınçları korele değildi ( $\mathrm{r}: 0.374, \mathrm{p}=0.073$ )

Klinikte ölçülen sistolik kan basıncı ile diyastolik kan basincı arasında kuvvetli ve pozitif yönlü bir korelasyonu vardı $(\mathrm{r}: 0,862$ $\mathrm{p}=0.000$ R: 0,743 )

Hastaların kısa süreli takiplerinde kaydedilen kan basıncı değerleri ile yaş, boy, kilo, BMI ve nabız sayıları arasında bir ilişki saptanmadı $(\mathrm{p}>0.05)$.

\section{Tartışma}

Noninvaziv kan basıncı ölçüm teknikleri; uygulanması kolay, kolaylıkla otomatize edilebilen, enfeksiyon riski ihmal edilebilir düzeyde olan yöntemlerdir. Yaygın kullanımlarına rağmen, indirekt kan basıncı ölçüm tekniklerin doğruluğu ve güvenirliği konusunda tereddütler vardır (1). Bu konuda daha düzenli ve sistematik çalışmalara ihtiyaç olduğunu düşündüğümüz için bağıml örneklemlerden oluşan bu çalışmamızı planladık ve toplam 46 hasta ile çalışmamızı tamamladik.

İnvaziv kan basıncı ölçümleri ile noninvaziv yöntemleri karşılaştıran çalışmaların sayıları kısitlıdır (2-4). İlk defa Köhler M ve ark.'ları invaziv olmayan doppler ultrason tekniği ile intraarteryel sistolik basıncı karşılaştırmış ve bu tekniklerini güvenilir bulmuşlardır (3). Ancak Köhler ve arkadaşları çalışmalarında diyastolik kan basıncını, tekniğin kendisinden kaynaklı olarak net ölçememiştir. Gravlee ve ark'ları 4 farklı indirekt ölçüm yöntemi ile intraarteryel kan basınc1 değerlerini karşılaştırmış ve diyastolik kan basıncı 
Şekil 1: Çalışma hastalarındaki sistolik kan basıneı ortancaları

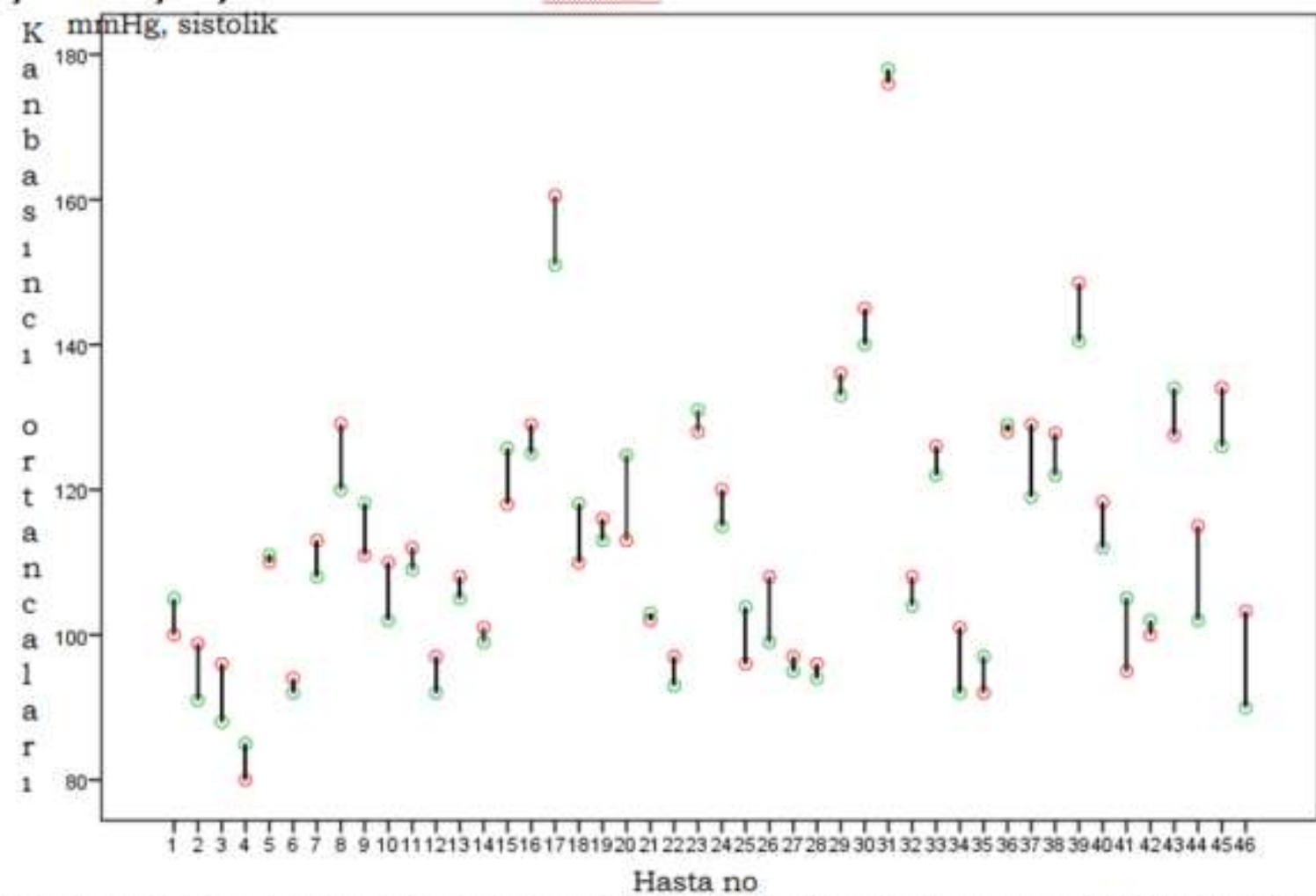

Kırmızı ve yeşil renkli halkalar eşzamanlı olarak elde edilen iki ayn ölçüm yönteminin ortancalarin temsil etmektedir.

Şekil 2: Çalışma hastalarındaki diyastolik kan basıncı ortancaları

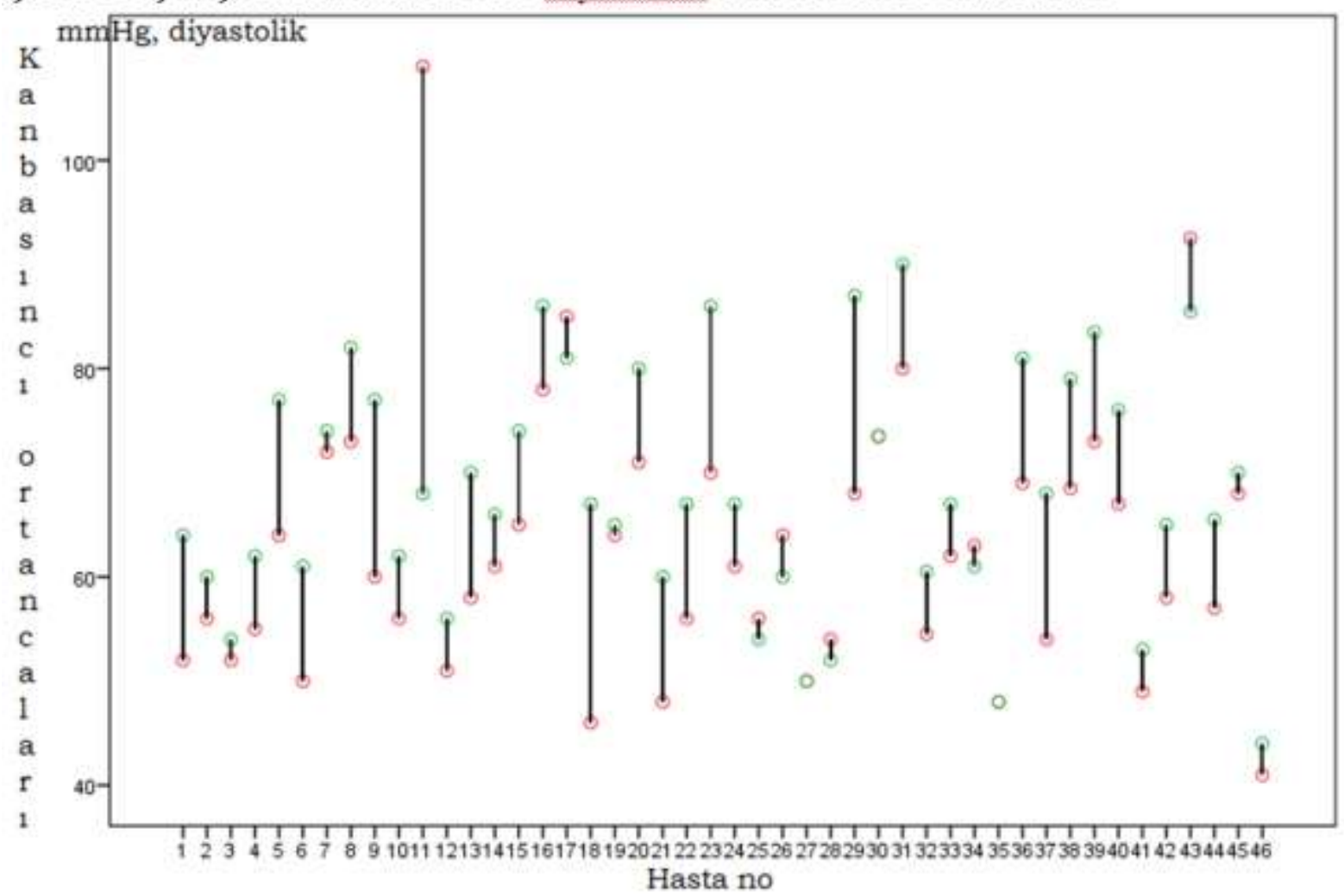

Kırmızı ve yeşil renkli halkalar eşzamanlı olarak elde edilen iki ayrı ölçüm yönteminin ortancalarin temsil etmektedir. 
haricindeki diğer basınç parametrelerini birbirleri ile korele bulmuşlardır (2). 2000'li yılların başında Sagiv ve arkadaşları sağlıklı normal bireylerde izometrik egzersizlerde yaptıkları iki çalışmada diyastolik tansiyonun direkt ve indirekt tekniklerde ölçülenlerle iyi korele olmadığını bildirmişlerdir $(4,5)$ fakat katılımcı sayılarının çok az olmasından dolayı bu çalışmaları fazla ses getirmemiştir. Daha sonra da ölçümler arasında ki diyastolik kan basınc1 uyumsuzluğu konusu bilimsel camianın pek ilgisini çekmemiştir.

Giriş kısmında da belirttiğimiz gibi manşonla ölçülen sistolik kan basıncı ölçümü kaf söndürülürken arteryel kanın boş damar yatağ 1 içine birden akarken oluşturduğu seslerin duyulması ile elde edilmektedir. Manşon kafının söndürülmesinin bir safhasında arteryel kanın akım seslerinin duyulduğu son değer diyastolik kan basıncını vermektedir. $\mathrm{Bu}$ yöntemle gerçek diyastolik basıncı ölçmek mümkün değildir. Aslında teorik olarak manşonla ölçümlerde hem sistolik hem de diyastolik kan basıncı değerinde kalbin sistolik atım gücü ölçülmektedir. Bu ölçümler arasında değişen tek şey bizim ekstremitelerdeki artere, manşonun şişirilmesi vasitasıyla dişardan uyguladığımız basınçtır. Bir noktada basınç o kadar yükselir ki arter kan akımı durur ve kalp atımlarının periferik yansımaları hissedilmez ve arter üzerine koyduğumuz stetoskoptan hiç ses duyulmaz. Diğer bir noktada ise dişardan arter üzerine verilen basınç azaltılırken kalbin sistolik output gücü ile arter içerisine kan akımı başlar ve biz stetoskop ile kalp atımlarının periferik yansımalarını duymaya başlarız. Dışardan azalan basınçla birlikte arter lümenindeki kan akımı rahat akmaya

\section{KAYNAKLAR}

1. Murphy GS, Vender JS. Monitoring the Anesthetized Patient. In: Barash, Paul G.; Cullen, Bruce F.; Stoelting, Robert K. Eds. Clinical Anesthesia, 5th Edition. Lippincott Williams \& Wilkins 2006:668-675

2. Gravlee GP, Brockschmidt JK. Accuracy of four indirect methods of blood pressure başlar ve belirli bir noktadan sonra bu arteryel sesler duyulmaz hale gelir. Yani özetle biz manşon kullanarak iki farklı basınç altında aynı sistolik basıncın ölçüldüğünü iddia ediyoruz.

Üzerinde durulması gereken ikinci bir husus da diyastolik ve sistolik basınçların birbirine bağımlı değişken olmalarıdır. Diyastolik kan basinc1, kalbin diyastolde iken damarlarda ve kalpte kalan kanın damar ve kalp duvarlarına yaptığı basıncın değeridir. Kardiyak output ne kadar fazla ise sistolik kan basincı o kadar yüksek olur ve perifere o kadar fazla kan pompalanır. Perifere pompalanan kan ne kadar fazla ise kalbin diyastol safhasında ölçülecek kan basıncı da o kadar yüksek olur. $\mathrm{Bu}$ da sistolik ve diyastolik kan basınçlarının birbirine bağıl değişkenler olduğu anlamına gelir. Bu bağıllıktan dolayı manşonla ölçülen sistolik ve diyastolik kan basıncı değerleri kısmen gerçeği yansıtmaktadır. Bundan dolay1 yıllardır manşonla ölçülen 'küçük tansiyon' değerleri diyastolik kan basınc1 olarak kabul edilmektedir.

Biz çalışmamızda manşonla ölçülen diyastolik kan basınç değerleri ile intraarteryel ölçülen diyastolik kan basıncı değerleri arasında bir korelasyon bulamadik. Fakat bir önceki paragrafta bahsettiğimiz tezimizi destekler nitelikte manşonla ölçülen sistolik ve diyastolik kan basınçları arasında kuvvetli pozitif bir ilişki tespit ettik.

Sonuç olarak diyastolik kan basıncı gerçek değerlerinin yeni bir teknik geliştirilinceye kadar yalnızca invaziv yöntemlerle ölçülebileceği kanaatindeyiz.

Çalışmamızda çıkar çatışması bulunmamaktadir.

measurement, with hemodynamic correlations. 1990 Oct;6(4):284-98.

3. Köhler M, Lösse B. Z Kardiol. Simultaneous measurement of indirect (Doppler-ultrasonictechnique) and direct arterial systolic blood pressure of the human radial artery. 1979 Aug;68(8):551-6.

4. Sagiv M, Ben-Ska D., Goldhammer E. Direct vs. Indirect Blood Pressure Measurement at Peak 
Anaerobic Exercise. Int J Sports Med 1999; 20(5): 275-278

5. Sagiv M, Hanson P.G., Ben-Ska D., Nagle F. J. Direct vs Indirect Blood Pressure at Rest and
During Isometric Exercise in Normal Subjects. Int J Sports Med 1995; 16(8): 514-518.

Corresponding author e-mail: ibrahim.yildirim@sbu.edu.tr

Orcid ID:

Ibrahim Yıldırım 0000-0003-4064-1753

Doi: $10.5505 /$ aot.2021.14880 